American Journal of Applied Sciences 6 (9): 1763-1769, 2009

ISSN 1546-9239

(C) 2009 Science Publications

\title{
The Effect of Technology Transfer Factors on Performance: An Empirical Study of Libyan Petroleum Industry
}

\author{
${ }^{1}$ A.S. Mohamed, ${ }^{2}$ S.M. Sapuan, ${ }^{3}$ M.M.H. Megat Ahmad, \\ ${ }^{4}$ A.M.S. Hamouda and ${ }^{2}$ B.T. Hang Tuah Bin Baharudin \\ ${ }^{1}$ Institute of Advanced Technology, University Putra Malaysia, \\ 43400 UPM Serdang, Selangor, Malaysia \\ ${ }^{2}$ Faculty of Engineering, University Putra Malaysia, 43400 UPM Serdang, Selangor, Malaysia \\ ${ }^{3}$ Faculty of Engineering, University Pertahanan National Malaysia, 57000 UPNM, \\ Kem Sungai Besi, Kuala Lumpur, Malaysia \\ ${ }^{4}$ Mechanical and Industry Systems Engineering Qatar University, \\ P.O. Box 2713, Doha, Qatar
}

\begin{abstract}
Problem statement: In Libya, like most petroleum producing countries, attempts began to develop the petroleum industry through several frames of Technology Transfer (TT). The realization of TT is progressively more forecasted with a starting point of essential factors mainly government support, Knowledge base, environment, Willingness to learn and anticipated to rely more on these factors further in the future. Approach: This study evaluated the degree of significance for the government support, knowledge base, environment and the willingness to learn after years of implementing industry standards, importing technology and training employees and joint ventures with advanced companies were applied to the Libyan petroleum industry. Results: The TT performance factor measurements were derived from a questionnaire survey conducted recently on the Libyan petroleum industry, which involved in TT process. With response rate of $68.35 \%$, the findings showed that the TT performance correlates with the level of readiness of environment, knowledge base, willingness to learn factors and the influential role of government support factor in the Libyan petroleum industry. Conclusion: Hence, results implied or even established that successful performance of TT, which able to cultivate petroleum industry employees can provide a broader spectrum of benefits to the petroleum industry.
\end{abstract}

Key words: Technology transfer, petroleum industry, government support

\section{INTRODUCTION}

Over the last 40 years, the fast growing petroleum producing countries has experienced rapid petroleum industrialization and economic growth. Much of this development can be attributed to Technology Transfer (TT). The petroleum industry of Libya is no exception, experiencing unprecedented growth through the formation of large petroleum complexes and petroleum related infrastructure programs that are largely partnered with foreign companies. Such programs have undoubtedly escalated the turnover of the petroleum sector in Libya. Nevertheless, the question remains, whether Libyan petroleum professionals are gaining best practice knowledge and technologies, ultimately reducing their reliance on foreign multi-nationals through the creation of internationally competent and competitive indigenous professionals. The Libyan government, the Libyan National Oil Corporation (NOC) and the foreign companies, have a vested interest in ensuring that technology is being transferred at an acceptable rate. However, although TT is touted as a key objective of large petroleum infrastructure projects, they are often commissioned without any structured policies or guidelines for measuring the rate of TT diffusion to the Libyan petroleum professionals, companies and the industry at large. Measuring the performance of TT at these levels, provides opportunities for all petroleum industry participants to better gauge deficiencies in TT process and ensure that expected outcome are being delivered.

In an attempt to measure the TT process in the Libyan petroleum industry, to addresses the effect of government support on the TT performance of Libyan

Corresponding Author: Almabruk Mohamed, Institute of Advanced Technology, University Putra Malaysia,

43400 UPM Serdang, Selangor, Malaysia Tel: +60126789448 
petroleum industry. The baseline of the study investigation was constructed utilizing a framework, which includes a number of factors and associated indicators that capture all the enablers of TT process and the outcome it created for the Libyan petroleum industry. In recent years, there have been a number of researchers, which have studied the TT process and some TT studies have been examined. However, whilst many of these studies were developed for the business and manufacturing sectors, the author is not aware of any comprehensive TT model developed specifically for examining TT on petroleum industry ${ }^{[1]}$. Such a model would need to be developed through a process of justifying, grouping, linking and refining factors established across a number of different industry sectors. As a result, the need arise to examine existing studies developed across all industry sectors with the view to evaluate a TT factors effect, which is specifically intended for the petroleum sector.

Studies conducted by Benedetto et al. ${ }^{[2-9]}$ were explored; examined and critically reviewed. However, the studies explored in the literature mostly are experimental studies that give an insight to the TT concept. Nevertheless, some differences in models that are indicated below acknowledge the differences in aims, especially in the petroleum industry. Calantone's ${ }^{[3]}$ framework designed mainly to get feedback on TT process. The environment factors are considered influential in any study. Notwithstanding, Calantone's study was based on comparative marketing research which has no indicators for TT performance, very complex in design and not empirically verified. The Simkoko ${ }^{[7]}$ model was mainly designed for assessing the local firm's involvement in TT process. Furthermore, the model is concerned of management teams' organization and interaction. Moreover, Simkoko study has a limited understanding of TT process and has no indicator on the TT performance impact. In Kumar's ${ }^{[4]}$ learning model, the learning culture in integrated in the capability assessment model. In addition, it was designed for small-scale manufacturing industries and the model's sample size was small. Lin and Berg ${ }^{[5]}$ have detailed description of the effect of technology complexity and the level of experience that considered important components of TT model. However, model findings maybe considered biased because it was based on only two Taiwanese manufacturing companies and designed to study long term management practice, failing to detail sufficient description of important TT factors. The "broadcasting" model of Malik $^{[6]}$ provided good insights on TT process; the model was useful in terms of its characteristics. Unfortunately, it was tested on one company, which may be too considered empirically biased. Wang, Tong et al. ${ }^{[8]}$ based on two enablers that is knowledge and the parent organization effect but fails to examine important factors such as government role and complexity of technology. Finally, the modeling of Waroonkun and Stewart ${ }^{[9]}$ which was statistically verified has identified most of the influential factors and the model overall is easy to adopt to any other industry TT process. Nevertheless, it was designed for construction industry and may not be accurate to other industries. In addition, the model depends on the maturity level of the host nation level of technology. This study is consisted of a set of enablers including: Government Support, Knowledge Base, Environment and Willingness to Learn and aimed to measure the TT performance.

\section{MATERIALS AND METHODS}

The selection of the questionnaire survey as preferred method of data collection for this study was on two reasons. One reason, other data collection methods such as interview sheets, rating scales or a phone questionnaire seems almost impossible to be applied in the Libyan petroleum industry because of the high cost and the administrative approach in the industry. An important reason is that the questionnaire survey reduces the risk of social desirability bias associated with self administration ${ }^{[10]}$. Questionnaire is designed to provide a general answer to the research question of the study, including the issues that have been examined in previous published or unpublished studies, which can be found on the issue. The questionnaire also provides several options for respondents for answering the questionnaire and provides enough time for respondents provide the correct information required for the questionnaire. The objective of questionnaire design is to concentrate on all research questions. Each question in the questionnaire survey signifies a factor or number of sub factors that needs to be measured in the population. These factors are translated into questionnaire questions, which allow respondents to provide information on these factors. Questionnaire consists of a set of questions written to the very meaning of what is required of the search query. This study is confined to investigating only the Libyan petroleum industry and specifically the NOC fully owned petroleum companies and joint ventures companies.

A survey was carried out on the sample targeting petroleum companies' employees who has involved in TT processes. TT processes was defined as some form of knowledge, material or equipments is transferred on 
petroleum industry from one foreign party such as a person or organization to another local (Libyan) party as a person or organization that arrange to receive it. Thus, respondents from Libya's petroleum industry were considered the best respondents to evaluate the learning environment factors and their effect on variables pertaining to the TT process and the performance it can potentially generate. To achieve the objective of the questionnaire survey, the 6-page survey was structured as recommended by ${ }^{[11,12]}$. The total petroleum employees in Libya, according to NOC statistics are 45000 employees. As expected, it was difficult to determine the adequate number of sample participants for this study. However, this process made use of available statistics on the NOC and statistics of the Libyan petroleum companies available and counseling with professional academics in the relevant statistical research, the approximate number of employees involved in TT related past and present petroleum projects was determined to be about 5000 employees. The total numbers of (300) questionnaires were distributed. Completed questionnaires responses of (205) were received, the rates were $68 \%$. Statistical methods used to analyze the data using statistical package (SPSS ver. 15) which was utilized in this research for quantitative analysis due to its accuracy and effectiveness.

Data analysis: To determine if data on quantitative variables are normally distributed ${ }^{[13,14]}$ recommended that the Kolmogrov-Smirnov test be used. The test indicated that the data collected were indeed accordingly $(\mathrm{p}<0.05)$. In addition, to ensure the accuracy of the results, validity and reliability were carefully considered in the construction of scale ${ }^{[15]}$. The questionnaire was structured in seven sections to collect information on the industry and for the responses to diverse subjects. Some information on the questionnaire and analyses of data are given below.

Internal consistency reliability: The question of reliability rises as the function of scales is expanded to include the area of forecast. One of the most popular reliability statistics in use today is Cronbach's alpha ${ }^{[16]}$. Cranach's alpha determines the internal consistency or average correlation of items in a survey instrument to gauge its reliability. The reliability of the 5 point Likert scale used for measuring TT performance on the items surveyed was determined by Cronbach's alpha coefficient. According to Ullman et $a l^{[13]}$ and Sekaran ${ }^{[17]}$, the coefficient should be greater than 0.7 for the scale to be reliable. The results were $0.738-0.872$.
Table 1: Cronbach's alpha for internal consistency

\begin{tabular}{lll}
\hline Factor & No. items & Cronbach's alpha \\
\hline Government support & 4 & 0.773 \\
Knowledge base & 4 & 0.738 \\
Environment & 4 & 0.788 \\
Willingness to learn & 4 & 0.760 \\
Performance & 3 & 0.872
\end{tabular}

Table 1 shows that the Cronbach's $\alpha$-values for the five components of Government Support, Knowledge Base, Environment, willingness to learn and TT performance were all greater than 0.7 . Nunnaly ${ }^{[18]}$ has indicated 0.7 to be an acceptable reliability coefficient. From the result, it can be concluded that this instrument is reliable.

\section{RESULTS}

Descriptive statistics: According to Chrisman and McMullan $^{[19,20]}$ the government support provides growth and innovation showing a positive effects on the industry. Additionally, Chrisman and Katrishen ${ }^{[21]}$, suggested that the government support plays an important role to help national industry to grow. The Government Support for TT in Libyan petroleum Industry involved the laws and regulation and government programs for TT and NOC support in terms of strategy and reward system. Figure 1 shows that the effect of laws and regulations was higher at $(55.1 \%)$ of the respondents, followed by NOC strategy at $(51.7 \%)$. However, government plans and reward system have almost equal response of $(42 ; 42.4 \%)$ respectively.

Figure 2 shows the impact of knowledge base factor with IT knowledge (54.6\%), followed by the technical training $(47.3 \%)$, the research and developments impact (41.5\%) and applying international quality standards impact was rated positively at (39\%).

Figure 3 shows the status of TT environment in Libyan petroleum industry, experience of Libyan petroleum employees working with foreign companies (54.6\%) and communication between foreign and Libyan companies (47.3\%), the industry technical skills (41.5) and teamwork between foreign and local companies at (39\%) impact.

Figure 4 shows that willingness to learn effect, the differences in culture (54.6\%), the capability to utilize the already available foreign technology $(47.3 \%)$, the attitude towards foreign technology $(41.5 \%)$ and the degree of exposure to foreign technology at (39\%). 


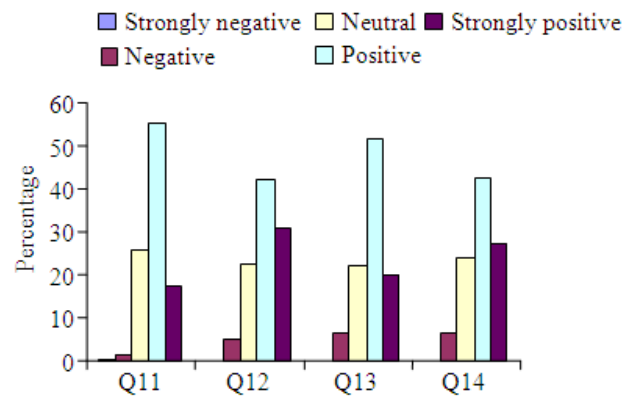

Fig. 1: Government support impact

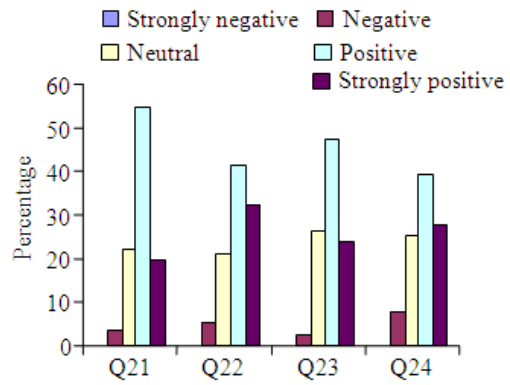

Fig. 2: Knowledge base rating

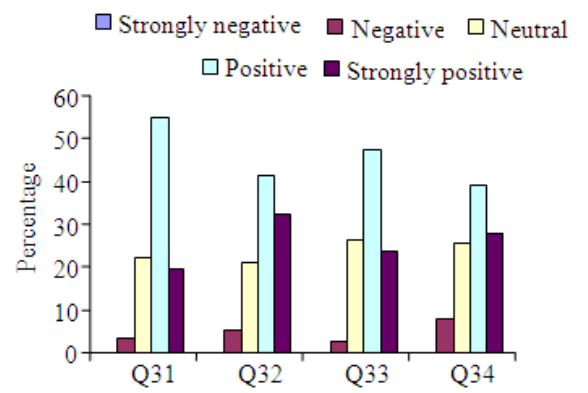

Fig 3: Environment factor impact

Correlation matrix of the support variables: Correlation is one of the most common and useful statistical tool, it gives a coefficient that describes the degree of relationship between variables. It is a measure of the strength of the linear relationship between two measurable variables. The Pearson correlation coefficient, represented as $r$, gives the strength and direction of this relationship. The closer $r$ is to 1 or to 1 then the stronger the linear relationship between the two variables. The usefulness of the correlation depends on its size and significance. If $\mathrm{r}$ reliably differs from 0.00 , the r-value will be statistically significant (i.e., does not result from a chance occurrence) implying that if the same variables were measured on another set of similar subjects, a similar r-value would result.

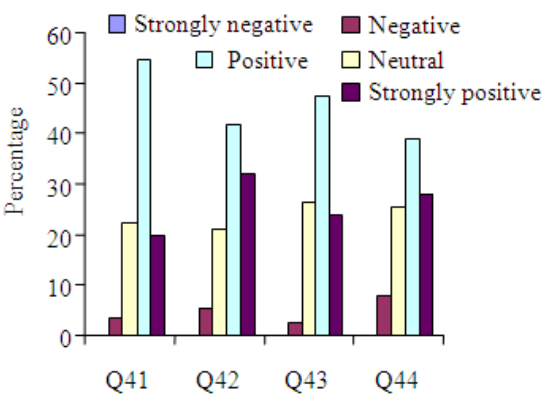

Fig 4: Willingness to learn effect

Table 2: Analysis of correlation degree for TT variables $(\mathrm{N}=205)$

\begin{tabular}{llllll}
\hline \multicolumn{1}{l}{ TTGS } & TTKB & TTE & TTWL & TTP \\
\hline Independent variables & & & & & \\
TTGS & 1.000 & & & & \\
TTKB & $0.751^{* *}$ & 1.000 & & & \\
TTE & $0.662^{* *}$ & $0.700^{* *}$ & 1.000 & & \\
TTWL & $0.631^{* *}$ & $0.680^{* *}$ & $0.766^{* *}$ & 1.000 & \\
Dependant variable & & & & & \\
TTP & $0.737^{* *}$ & $0.677^{* *}$ & $0.656^{* *}$ & $0.684^{* *}$ & 1 \\
\hline **: Correlation is & significant at the 0.01 & level (2-tailed); Where: \\
TTGS: TT Government Support; TTKB: TT Knowledge Base; TTE: \\
TT Environment; TTWL: TT Willingness to Learn; TTP: TT \\
Performance
\end{tabular}

If $r$ achieves significance, we conclude that the relationship between the two variables was not due to chance. In this study, the variables were examined using Pearson's 2-tailed test. In the correlation matrix in shown in Table 2, all the perceptions from the respondents in five areas were significantly correlated with each other individually. Government Support (TTGS) had a significant positive relationship with Technology Transfer Performance (TTP) at $\mathrm{p}<0.01$, Knowledge Base (TTKB) was highly correlated with TTP at $\mathrm{p}<0.01$ and Environment (TTE) positively related with TTP at $\mathrm{p}<0.01$. Technology Transfer Willingness to Learn (TTWL) was significance with TTP at $\mathrm{p}<0.01$. TTE has the largest correlation with TTWL is equal to 0.766 at $p<0.01$. Results shown than the degree of association between variables are highly significant.

Regression model: A linear regression with two or more predictors whose coefficients are found to minimize the sum of the squared residuals is a least squares linear multiple regression. However, it is usually just called a multiple regression. When the distinction is needed, a least squares linear regression with a single predictor is called a simple regression. The multiple regression model equation $(\mathrm{Y})$ is consists of predictors (X's), regression coefficients that estimate from the data (B's) and including the Errors (E):

$\gamma=\beta_{0}+\beta_{1} * \chi_{1}+\beta_{2} * \chi_{2}+\ldots . \beta n * \chi_{n}+\varepsilon$ 
Am. J. Applied Sci., 6 (9): 1763-1769, 2009

Table 3: Model summary of multiple regression

\begin{tabular}{llllll}
\hline Model & $\mathrm{R}$ & $\mathrm{R}^{2}$ & Adjusted $\mathrm{R}^{2}$ & Std. error of the estimate \\
\hline 1 & $0.795(\mathrm{a})$ & 0.632 & 0.625 & 0.37777 & \\
\hline Predictors: & (Constant), & TTGS, & TTKB, & TTE, TTWL; Dependent
\end{tabular}
Variable: TTP

Performance Vs government support, knowledge base, environment, willingness to learn: Regression analysis of the TTP metrics (TTGS, TTKB, TTE and TTWL) indicated that TT performance positively influenced performance with a coefficient of determination $\left(\mathrm{R}^{2}\right)$ of 0.632 . This indicates that $63.2 \%$ of the TT performance was explained collectively by government support, knowledge base, environment and willingness to learn. The F-and t-tests were used to assess the goodness-of-fit of the models and their individual parameters, respectively. Associated with each test is a p-value that expresses the probability that the result of the test is significant. A probability of less than 0.05 is generally considered the highest to indicate a significant difference Fox ${ }^{[23]}$. For the TTP regression model, the p-value was 0.000 (less than 0.001 ) for the F-test 85.899 and 2.821 for the t-test. These probabilities allowed the null hypothesis to be excluded and the model and factor assumed satisfactory. The histogram explains the model with normal distribution, mean of 9.7 and Standard Deviation of 0.99 .

Multiple regression analysis: Multiple regression analysis estimates the coefficients of a linear equation, involving one or more independent variables, which best predict the value of the dependent variable. Table 3 shows the relationship between a dependent variable (TTP) and multiple independent variables (TTGS, TTKB, TTE and TTWL). R, R squared, adjusted R squared and the standard error were obtained from the model. $\mathrm{R}$ is the correlation between the observed and predicted values of the dependent variable. The values of $\mathrm{R}$ range from -1 to 1 . The sign of $\mathrm{R}$ indicates the direction of the relationship (positive or negative). The absolute value of $\mathrm{R}$ indicates the strength, with larger absolute values indicating stronger relationships.

$\mathrm{R}$ squared is the proportion of variation in the dependent variable explained by the regression model. The values of $\mathrm{R}$ squared range from 0-1. Small values indicate that the model does not fit the data well. The sample $\mathrm{R}$ squared tends to optimistically estimate how well the model fits the population. Adjusted R squared attempts to correct $\mathrm{R}$ squared to more closely reflect the goodness of fit of the model in the population.
Table 4: Analysis of variance

\begin{tabular}{|c|c|c|c|c|c|}
\hline Model & Sum of squares & df & Mean square & $\mathrm{F}$ & Sig. \\
\hline Regression & 49.034 & 4 & 12.259 & 85.899 & $0.000 \mathrm{a}$ \\
\hline Residual & 28.542 & 200 & 0.143 & & \\
\hline Total & 77.576 & 204 & & & \\
\hline
\end{tabular}

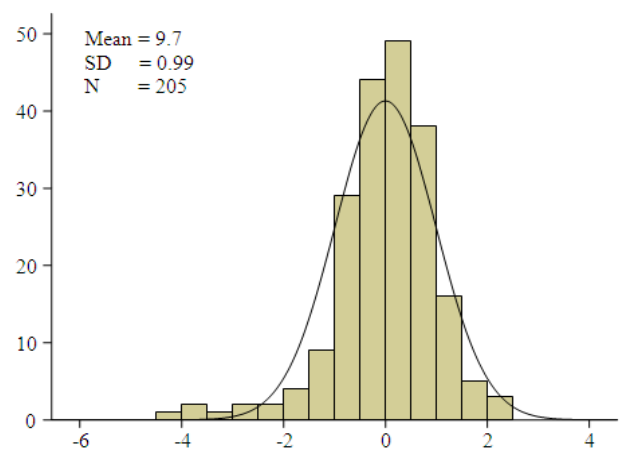

Fig. 5: TTP regression standardized residuals

The results of the Analysis of Variance (ANOVA) are shown in Table 4. The ANOVA Table 4 tests the overall significance of the model (that is, of the regression equation). If we had been doing stepwise regression, significance for each step would be computed. Here the significance of the F-value is below 0.05 , so the model is significant.

Regression equation: The regression coefficient for a variable indicates how much change there will be in the predicted score when there is a one-unit change in the in this variable with all of the other variables in the model held constant:

$$
\begin{aligned}
\text { TT performance }= & 0.543+0.413 * \text { government } \\
& \text { support }+0.112 * \text { knowledge } \\
& \text { Base }+0.08 *^{*} \text { environment }+0.265 * \\
& \text { willingness to learn. }
\end{aligned}
$$

Both histogram of residuals shown in Fig. 5 and normal probability plot shown in Fig. 6 from the regression model seem to have normal distribution. This further substantiated by the observed KolmogorovSmirnov test of normality applied.

It is often very useful to look at the standardized residual versus standardized predicted plot in order to look for outliers and to check for homogeneity of variance. The ideal situation is to see no observations beyond the reference lines, which means that there are no outliers. In addition, we would like the points on the plot to be distributed randomly, which means that all the systematic variance has been explained by the model. 
Table 5: Standardized regression coefficients

\begin{tabular}{lll}
\hline Variable & Beta coefficient & $\mathrm{P}$ \\
\hline TTGS & 0.413 & $* * *$ \\
TTKB & 0.112 & \\
TTE & 0.088 & $* * *$ \\
TTWL & 0.265 & $*$ \\
\hline
\end{tabular}

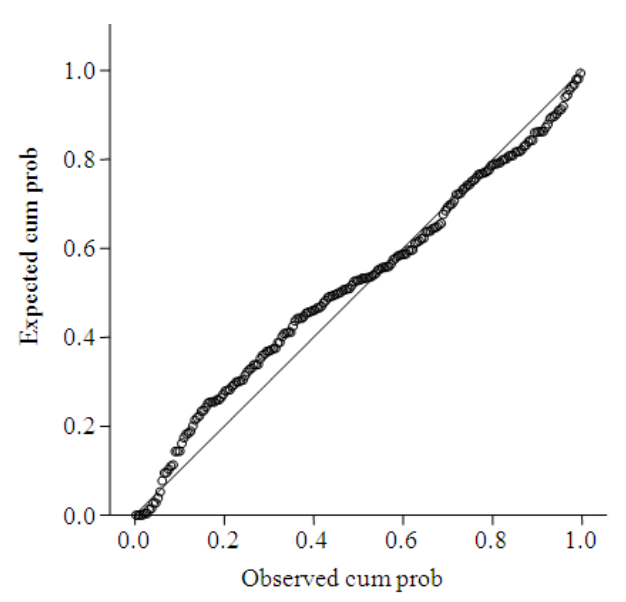

Fig. 6: Normal P-P plot of regression standardized residual

\section{DISCUSSION}

The incentive of our study was to determine the impact of TT factors on TT performance in Libyan petroleum industry. A survey questionnaire was proposed and empirical testing was performed using a sample of 205 petroleum professionals involved in TT processes.

Our result provided insights on the effect of the government support, knowledge base, environment and willingness to learn factors on the performance of TT processes in the industry. Although, multiple regression provide the indicator to the combined factors, however, it will hint to each factor importance. Government support and willingness to learn factors were found to have a significant effect on TT performance and strong government influence on the knowledge base and TT environment. Knowledge base and environment factors, however, were found to be insignificant indicating lack of sufficient consideration to these factors. The decision makers should carefully examine the absorption of knowledge and skills in the industry. Their strategy could be more effective when they recognized the importance of TT environment and should be in better position to build the required TT environment or performance levels.

\section{CONCLUSION}

This study provides empirical evidence that factors of TT have a positive impact on Libyan petroleum industry performance. The findings are relevant to both the petroleum industry and TT literature. It also identified and assessed the degree of TT effectiveness and investigated the factors that affected the performance of petroleum industry. The factors were government support, knowledge base, Environment and willingness to learn. Thus, government support, knowledge base, environment and willingness to learn would have to increase greatly if the TT performance is to be substantially improved. The model used was significant at $\mathrm{p}<0.01 \quad(0.000)$ with a coefficient of determination $\left(\mathrm{R}^{2}\right)$ of $0.632(63.2 \%)$ of the TT performance. The findings have proposition to the Libyan petroleum industry as it bestow a mechanism to help them evaluate its degree of TT performance. Furthermore, the finding assists the Libyan industry to be aware of the imperative of each factor in the TT process. One implication was that NOC should pay special consideration to the direct roles of knowledge base and environment of petroleum industry and especially focus on a holistic view to integrate knowledge base in the petroleum industry. It not enough to just expect that TT will naturally occur, the processes, which underpin TT, should be continuously evaluated to ensure that knowledge and local petroleum employees are seamlessly absorbing skills. Finally, a suggestion that government and Libyan petroleum industry should seriously start to invest funds into further developing acquired petroleum industry technology and knowledge management. Such funding will ensure that knowledge is perpetually building in domestic petroleum industry diminishing the degree of reliance on foreign companies.

\section{ACKNOWLEDGMENT}

The researchers would like to thank all the respondents who participated in the questioner survey. The authors also thank the Institute of Advanced Technology, University Putra Malaysia for their cooperation and the facilities provided. Special thanks are due to Libyan Secretariat of higher education for providing the financial support for this research. This support is gratefully acknowledged.

\section{REFERENCES}

1. Knight, K.E., 1984. Technology transfer in the petroleum industry. J. Technol. Transfer, 8: 27-34. DOI: $10.1007 / \mathrm{BF} 02175643$

2. Di Benedetto, C.A., R.J. Calantone and C. Zhang, 2003. International technology transfer: Model and exploratory study in the people's Republic of China. J. Int. Market. Rev., 20: 446-462. DOI: $10.1108 / 02561330310485171$ 
3. Calantone, R.J., M.T. Lee and A.C. Gross, 1990. Evaluating international technology transfer in a comparative marketing framework. J. Global Market., 3: 23-46. DOI: 10.1300/J042v03n03_03

4. Kumar, V., U. Kumar and A. Persaud, 1999. Building technological capability through importing technology: The case of Indonesian manufacturing industry. J. Technol. Transfer, 24: 81-96. DOI: 10.1023/A:1007728921126

5. Lin, B.W. and D. Berg, 2001. Effects of cultural difference on technology transfer projects: An empirical study of Taiwanese manufacturing companies. Int. J. Project Manage., 19: 287-293. DOI: 10.1016/S0263-7863(99)00081-2

6. Malik, K., 2002. Aiding the technology manager: A conceptual model for intra-firm technology transfer. Technovation, 22: 427-436. DOI: 10.1016/S0166-4972(01)00030-X

7. Simkoko, E.E., 1992. Managing international construction projects for competence development within local firms. Int. J. Project Manage., 10: 12-22. DOI:10.1016/0263-7863(92)90068-K

8. Wang, P., T.W. Tong and C.P. Koh, 2004. An integrated model of knowledge transfer from MNC parent to China subsidiary. J. World Bus., 39: 168-182. DOI: 10.1016/j.jwb.2003.08.009

9. Waroonkun, T. and R.A. Stewart, 2008. Modeling the international technology transfer process in construction projects: Evidence from Thailand. J. Technol. Transfer, 33: 667-687. DOI: 10.1007/s10961-007-9043-1

10. Biemer, P.P. and L.E. Lyberg, 2003. Introduction to Survey Quality. Wiley-Inter-Science, ISBN: 978-0-471-19375-3, pp: 424.

11. McQueen, R.A. and C. Knussen, 2002. Research Methods for Social Science: A Practical Introduction. Prentice Hall, ISBN: 10: 013040456X, pp: 245.

12. Andi, A. and T. Minato, 2003. Design documents quality in the Japanese construction industry: Factors influencing and impacts on construction process. Int. J. Project Manage., 21: 537-546. DOI: 10.1016/S0263-7863(02)00083-2

13. Tabachnick, B.G. and L.S. Fidell, 1996. Using Multivariate Statistics. 4th Edn., Allyn and Bacon Needham Heights, MA., ISBN: 10: 0321056779, pp: 966.
14. Pallant, J., 2001. SPSS Survival Manual: A Stepby-Step Guide to Data Analysis Using SPSS. Allen and Unwin, ISBN: 9781741144789 , pp: 336.

15. Leedy, P.D. and J.E. Ormrod, 2005. Practical Research: Planning and Design. 8th Edn., Prentice Hall, Upper Saddle River, New Jersey, ISBN: 10: 0131108956, pp: 352.

16. Cronbach, L., 1951. Coefficient alpha and the internal structure of tests. Psychometrika, 16: 297-334. http://www.citeulike.org/user/robertlischke/article/ 2731102

17. Sekaran, U., 2003. Research Methods for Business: A Skill Building Approach. 4th Edn., John Wiley and Sons, ISBN: 10: 0471384488, pp: 464.

18. Nunnaly, J.C., 1978. Psychometric Theory. 2th Edn., McGraw-Hill, ISBN: 0070474656, pp: 701.

19. Chrisman, J.J. and W.E. McMullan, 2000. A preliminary assessment of outsider assistance as a knowledge resource: The longer-term impact of new venture counseling. Entrepreneurship Theor. Pract., 24: 37-54. http://direct.bl.uk/bld/PlaceOrder.do?UIN=079908 $447 \&$ ETOC $=$ RN\& from $=$ searchengine

20. Chrisman, J.J. and W.E. McMullan, 2004. Outsider assistance as a knowledge resource for new venture survival. J. Small Bus. Manage., 42: 229-244. http://direct.bl.uk/bld/PlaceOrder.do?UIN=151862 $443 \& E T O C=R N \&$ from $=$ searchengine

21. Chrisman, J.J. and F. Katrishen, 1994. The economic impact of small business development center counseling activities in the United States: 1990-1991. J. Bus. Ventur., 9: 271-271.

DOI:10.1016/0883-9026(94)90008-6

22. Chrisman, J.J. et al., 1985. The impact of SBDC consulting activities. J. Small Bus. Manage., 23: 111. http://www.questia.com/googleScholar.qst?docId= 5001689125

23. Fox, J., 1997. Applied Regression Analysis, Linear Models and Related Methods. Sage Publications, ISBN: 10: 080394540X, pp: 624. 